\title{
Controle por Unidades Menores que a Palavra: Jogo de Tabuleiro Educativo Aplicado por Mães
}

\author{
Graziele Bueno de Farias Rebeiro Pellizzetti \\ Faculdade Assis Gurgacz, Cascavel, Paraná, Brasil \\ Silvia Regina de Souza ${ }^{1}$ \\ Departamento de Psicologia Geral e Análise do Comportamento da Universidade \\ Estadual de Londrina, Londrina, Paraná, Brasil
}

\begin{abstract}
Resumo
Objetivou-se investigar se um jogo de tabuleiro educativo, baseado no modelo de rede de relações e equivalência de estímulos, aplicado por mães, produz a leitura e a escrita das palavras ensinadas e de novas palavras formadas a partir da recombinação das sílabas dessas palavras. Participaram três díades (mãe e filho). As crianças frequentavam a educação infantil, tinham cinco anos de idade e desenvolvimento típico. O estudo foi realizado em cinco etapas: pré-teste, ensino do uso do tabuleiro às mães, intervenção/jogo, sonda e seguimento. Após a realização do estudo as mães responderam um questionário que avaliava o jogo como recurso pedagógico. O jogo possibilitava o ensino das relações entre palavra impressa, conjunto de sílabas, figura, escrita manuscrita e palavra falada. Os resultados mostraram que as mães aprenderam a usar o jogo e que o comportamento de elogiar o desempenho dos filhos foi mais frequente que os de punir e ou chamar sua atenção. Com o início da intervenção/jogo, houve aumento na porcentagem de acerto principalmente no respeitante às tarefas de emparelhamento entre palavra impressa e figura e escolha de acordo com o modelo com resposta construída. Embora tenha havido aumento na porcentagem de acertos de palavras de ensino lidas corretamente e de emparelhamentos corretos, este desempenho não se manteve ao longo das sessões. Todas as mães apontaram aspectos positivos do uso do jogo. Os resultados reafirmam a necessidade de tecnologias para o ensino de leitura e escrita que permitam o envolvimento dos pais e a necessidade de mais pesquisas na área.
\end{abstract}

Palavras-chave: Pais, leitura e escrita, jogos de tabuleiro, equivalência de estímulos, Análise do Comportamento.

\section{Control by Units Smaller than the Word: Educational Board Game Applied by Mothers}

\footnotetext{
Abstract

The present research aimed to investigate whether an educational board game, based on the relations network and stimuli equivalence model, applied by mothers, leads to the reading and writing of taught

Endereço para correspondência: Departamento de Psicologia Geral e Análise do Comportamento, Centro de Ciências Biológicas, Universidade Estadual de Londrina, Rod. Celso Garcia Cid, PR 445, Km 380, Caixa Postal 6001, Londrina, PR, Brasil 86051-990. E-mail: grabfr@gmail.com e ssouza@uel.br

Agradecimento: À Fundação Araucária.

Artigo elaborado a partir da dissertação de G. B. F. R. Pellizzetti, intitulada "O ensino de leitura e escrita e o controle por unidades menores que a palavra por meio de um jogo de tabuleiro aplicado por mães”, Universidade Estadual de Londrina, 2011.

Apoio financeiro: Bolsa Produtividade Fundação Araucária para S. R. de Souza.
} 
words and new words formed by the recombination of syllables from these words. Three dyads (mother and her son) participated in the study. The children, 5 years of age and of typical development, attend preschool. The study was carried out in five stages: pretest, teaching mothers the use of the board, intervention/game, probe and follow-up. After completion of the study, mothers answered a questionnaire that assessed the game as a pedagogical resource. The game allowed the teaching of the relationship between the printed word, a group of syllables, pictures, handwritten and spoken word. Results showed that the mothers learned to use the board game and that the behavior of praising children's performance was more common than reprehending them or calling their attention. With the beginning of the intervention/game, there was an increase in the percentage of pictures and words matched correctly and syllables selected correctly. Although there was an increase in the percentage of teaching words that were read correctly and of correct pairings, this performance did not remain constant throughout the sessions. All mothers indicated the positive aspects of the use of the board game. The results reaffirm the need for technologies to teach reading and writing skills which allow for the involvement of parents as well as the need for more research in the area.

Keywords: Parents, reading and writing, board game, stimulus equivalence, behavior analysis.

\section{Control por Unidades Menores que La Palabra: Juego de Mesa Educativo Aplicado por Las Madres}

\section{Resumen}

Este trabajo investigó si un juego educativo, basado en modelo de red de relaciones y de equivalencia de estímulos, aplicado por las madres, produce lectura y escritura de palabras enseñadas y nuevas palabras formadas por recombinación de sílabas. Participaron en díadas (madre e hijo). Los niños frecuentaban la educación temprana, tenían cinco años y desarrollo típico. El estudio se realizó en cinco etapas: antes de la prueba, enseñanza del uso de juegos a las madres, intervención/juego, sonda y seguimiento. Al fin del estudio ellas respondieron un cuestionario que evaluó el juego como recurso pedagógico. El juego permite la enseñanza de relaciones entre palabra impresa, conjunto de sílabas, figura, escrita manuscrita y palabra hablada. Los resultados mostraron que las madres aprendieron a utilizarlo y que el comportamiento de elogiar el desempeño era más común que castigar y/o llamar su atención. Al principio de la intervención/juego, hubo un aumento del porcentaje de éxito referido a las tareas de emparejamiento entre palabra impresa y figura y elección de acuerdo al modelo con respuesta construida. Aunque hubo un aumento del porcentaje de aciertos de palabras y enseñanza leídas correctamente y la pareja correcta, esta actuación no se mantuvo por las sesiones. Todas las madres destacaron aspectos positivos. Los resultados reafirman la necesidad de tecnologías para la enseñanza de lectura y escritura que permitan la participación de los padres y la necesidad de más investigación.

Palabras clave: Padres, lectura y escritura, juego de mesa, equivalencia de estímulos, análisis de la conducta.

Alguns autores apontam os efeitos positivos do envolvimento dos pais no aprendizado de conteúdos escolares de seus filhos (Marturano, 1999; Soares, Souza, \& Marinho, 2004; S. R. Souza, 2000). Envolvimento parental refere-se às interações dos pais durante a realização das atividades escolares, encorajamento verbal e reforço de comportamentos adequados que favo- reçam o desempenho acadêmico de seus filhos (Fehrmann, Keith, \& Reimers, 1987).

Apesar da importância do envolvimento dos pais, é comum as escolas, representadas pela figura do professor, queixarem-se da ausência deles no processo de aprendizagem. Em contrapartida, os pais, quando ouvidos, reclamam das dificuldades de concretização do envolvimento 
entre eles e a escola, principalmente quando se trata de pais com pouca escolaridade. Muitas vezes, o envolvimento dos pais com a vida acadêmica dos filhos limita-se ao auxílio nas tarefas escolares que, nem sempre, ocorre da maneira mais apropriada (Sampaio, Souza, \& Costa, 2004; Scarpelli, Costa, \& Souza, 2006). Apesar das dificuldades que alguns pais podem ter no respeitante ao ensino ou mesmo auxílio de conteúdos escolares específicos, quando bem orientados, eles podem contribuir para o maior engajamento de seus filhos nas atividades propostas pela escola. A valorização e o respeito por parte dos pais à vida escolar dos filhos pode, como afirma Hübner (1999), estimular a curiosidade, incentivar a busca de conhecimentos e, consequentemente, favorecer o desempenho acadêmico destes últimos. Por essa razão, constata-se a necessidade de desenvolver procedimentos que permitam ensinar aos pais repertórios que favoreçam o desempenho acadêmico de seus filhos, bem como o desenvolvimento de tecnologias que criem contextos mais reforçadores e, consequentemente, propiciadores de interações mais positivas entre pais e filhos.

No respeitante ao ensino de leitura e escrita, pesquisas que empregam o modelo de equivalência de estímulos têm sido desenvolvidas. De acordo com este modelo, a partir do ensino de algumas relações outras poderão emergir sem ensino explícito das últimas. O procedimento de escolha de acordo com o modelo (matching to sample [MTS]) tem sido utilizado para esse ensino. Nesse procedimento, à apresentação de um estímulo-modelo (estímulo condicional) segue-se a apresentação de, no mínimo, dois estímulos de escolha (estímulos discriminativos) diferentes; respostas que estejam de acordo com o critério estabelecido pelo pesquisador são seguidas por consequências reforçadoras. Por exemplo, após a apresentação da palavra CABO (estímulo-modelo), segue-se a apresentação das palavras CABO e BOCA (estímulos-comparação). A escolha da palavra $\mathrm{CABO}$, critério estabelecido pelo pesquisador, é seguida por consequências reforçadoras.

Apesar de as pesquisas nessa área apontarem a efetividade do modelo de equivalência de estímulos no ensino de leitura e escrita uma pessoa pode aprender a ler e escrever as palavras inteiras (e.g., LATA e BOCA) e não ser capaz de ler e escrever as palavras formadas pela recombinação das sílabas das palavras já aprendidas, por exemplo, BOLA, TALA, CABO e BOTA (S. R. Souza \& Hübner, 2010). O aprendizado de leitura e escrita pode acontecer a partir de processos de combinação, fragmentação e recombinação de unidades menores do que a palavra, o que demonstra não ser necessário o ensino de todas as palavras do nosso vocabulário (Matos, Hübner, Serra, \& Avanzi, 2002). A regularidade na correspondência fonética entre grafema e fonema presente na língua portuguesa favorece os processos de combinação, fragmentação e recombinação de unidades menores (de Souza \& de Rose, 2006). Estudos nessa área têm empregado o procedimento de escolha com o modelo com resposta construída ou CRMTS (de Rose, de Souza, \& Hanna, 1996; Dube, McDonald, McIlvane, \& Mackay, 1991; Hanna, Karino, Araújo, \& de Souza, 2010; Mackay \& Sidman, 1984; J. A. N. Souza \& Assis, 2013; S. R. Souza, Goyos, Silvares, \& Saunders, 2007; Stromer, Mackay, $\&$ Stoddard, 1992). Neste procedimento uma palavra é apresentada como modelo (ex., BOLA) e letras ou sílabas (ex., BO, LA, CA, MA etc.) são apresentadas como estímulos-comparação. Escolha das letras ou sílabas que compõem a palavra apresentada como modelo, na ordem correta, é reforçada.

Entre os trabalhos que investigaram os efeitos do envolvimento de pais no desempenho escolar de seus filhos e que empregaram o procedimento de CRMTS destaca-se o realizado por S. R. Souza et al. (2007). Esse estudo teve como objetivo verificar se pais de crianças consideradas suscetíveis de fracasso escolar aprenderiam a utilizar o procedimento de CRMTS para ensinar a seus filhos habilidades em leitura e escrita e se o trabalho desenvolvido pelos pais, junto às crianças, contribuiria para melhorar o desempenho acadêmico destas em leitura e escrita. Participaram cinco crianças com desenvolvimento típico de uma escola pública e suas respectivas mães.

As mães foram ensinadas a utilizar o procedimento de CRMTS nas fases de treino. Para 
isso, cada mãe recebeu um fichário de metal contendo cartões com letras do alfabeto impressas em preto dispostos em ordem alfabética e cartões brancos com palavras impressas em preto. As mães foram instruídas a colocar o cartão com a palavra impressa sobre a mesa (estímulo-modelo) e após um toque da criança sobre o cartão, a mãe distribuía aleatoriamente, sobre a mesa, as letras que formavam a palavra apresentada. A criança deveria escolher a primeira letra que formava a palavra-modelo e colocá-la logo abaixo dessa e, em seguida, fazer o mesmo com as demais letras. Inicialmente elas deveriam apresentar apenas as letras da palavra-modelo e gradativamente, ao longo das tentativas, acrescentarem mais letras ao conjunto anteriormente exposto, sendo que o número de letras apresentadas como estímulos-comparação não deveria exceder a 16.

Quando o estímulo-modelo era uma palavra ditada, as mães foram instruídas a ditar a palavra uma vez, repetindo apenas se necessário. Uma folha sulfite com a ordem na qual as tentativas deveriam ser apresentadas era entregue as mães no início da semana com a finalidade de auxiliá-las na realização das atividades, em casa. Nessa folha, a mãe deveria registrar, ao longo das tentativas, acertos e erros cometidos pelas crianças e, assim que a tarefa fosse concluída, ela deveria entregar a folha à pesquisadora. Nas fases de teste, os procedimentos eram realizados pela pesquisadora. As relações $\mathrm{AB}$ (palavra impressa - conjunto de letras) e BD (palavra falada - conjunto de letras) foram ensinadas. As relações DA (palavra falada - palavra impressa) e $\mathrm{AE}$ (palavra impressa - palavra falada pela criança) e escrita manuscrita foram testadas. Ao final, procedeu-se ao pós-teste de escrita manuscrita com as palavras ensinadas e as de generalização. Todas as crianças demonstraram ter aprendido as relações ensinadas e mostraram a emergência das relações testadas e escrita manuscrita correta das palavras. Um dos aspectos destacados por S. R. Souza et al. (2007) diz respeito ao fato de as mães participantes do estudo terem usado as letras não apenas para, por meio do procedimento de CRMTS, ensinarem as palavras de ensino do estudo aos seus filhos, mas também para brincarem com eles utilizando-se para isso de outras palavras que não faziam parte do estudo.

Segundo de Rose (2005), o uso de jogos e brincadeiras pode ser uma importante ferramenta para o ensino de pré-requisitos para os comportamentos de ler e escrever. Bomtempo (1999) caracteriza o jogo educativo como instrumento que permite ao educador o desenvolvimento de novas habilidades de seus alunos. De acordo com Skinner (1968/1972), jogos e brinquedos possuem consequências naturalmente reforçadoras e pouca ou nenhuma consequência aversiva o que pode levar as crianças a brincarem por horas. O jogo estabelece contingências de ensino diferentes das atividades formais trabalhadas pela escola e, portanto, poderia ser usado pelos pais como um recurso para o ensino de leitura e escrita (Ferreira et al., 2012; S. R. Souza \& Hübner, 2010; Xander, 2013). Em razão dos objetivos deste trabalho destaca-se a pesquisa conduzida por S. R. Souza e Hübner (2010).

O estudo de S. R. Souza e Hübner (2010) teve como objetivo investigar os efeitos da utilização do jogo de tabuleiro AbraKedabra: Construindo Palavras, de S. R. Souza (2007), na aquisição de leitura e escrita das palavras ensinadas (i.e., palavras de ensino) e de novas palavras formadas a partir da recombinação das sílabas dessas palavras (i.e., palavra de generalização). Participaram do estudo nove crianças que frequentavam a Educação Infantil de uma escola pública. As crianças, com desenvolvimento típico, tinham entre 5 e 6 anos e não sabiam ler ou escrever palavras dissílabas simples. Foram utilizadas nove palavras de ensino e nove palavras de generalização formadas pela recombinação das sílabas das palavras de ensino.

O estudo foi composto por quatro etapas: (a) Pré-Teste, (b) Intervenção/jogo, (c) Sonda e (d) Pós-Teste. No Pré-Teste, testaram-se as relações entre palavra impressa e palavra falada pela criança, entre palavra falada e conjunto de sílabas, entre palavra falada e escrita manuscrita e entre figura e palavra impressa. Posteriormente realizaram-se 15 sessões com o jogo de tabuleiro. O jogo é composto por 46 casas que visam ensinar as relações entre palavra impressa e conjunto de sílabas, figura, escrita manuscrita e palavra falada, conjunto de sílabas, figuras e 
escrita manuscrita. Ele tem início com a entrega de uma ou mais palavras impressas à criança que deverá lê-la em voz alta com ou sem ajuda. Em seguida, tendo como estímulo-modelo à palavra impressa e como estímulos-comparação as casas que compõem o tabuleiro, ela deverá construir a palavra, a partir das sílabas ganhas durante o jogo. O jogo termina quando a palavra impressa for construída (palavra impressa - conjunto de sílabas) e emparelhada com a figura correspondente (palavra impressa - figura). Outras tarefas exigidas no jogo são: cópia, ditado, soletração e nomeação. Na fase de Sonda e Pós-teste, foram testadas as mesmas relações do Pré-Teste. Verificou-se aumento no número de palavras corretamente lidas, de sílabas das palavras corretamente selecionadas, de emparelhamentos corretos entre figura e palavras e de sílabas corretamente escritas.

Quanto às palavras de generalização, constatou-se um aumento no número de sílabas corretamente selecionadas embora os testes de leitura e escrita dessas palavras não tenham mostrado mudanças expressivas. O pequeno número de sessões com cada palavra - cada criança brincou com uma mesma palavra por, no máximo, duas vezes e a sessão de intervenção/jogo teve duração aproximada de 40 minutos - e o fato de as palavras de ensino deste estudo não terem sílabas que ocupassem posições sistematicamente variadas nas palavras e repetição das sílabas pode ter contribuído para os resultados observados no respeitante às palavras de generalização. O desempenho das crianças com as palavras de ensino, contudo, sugerem que o jogo pode ser uma ferramenta interessante para o ensino de habilidades envolvidas no ler e escrever.

Diante do que foi descrito anteriormente, realizou-se a replicação do trabalho de S. R. Souza e Hübner (2010), visando expandi-lo a novos aplicadores/jogadores (mães) com a finalidade de investigar se mães aprenderiam as regras do jogo de tabuleiro Abrakedabra: Construindo Palavras (S. R. Souza, 2007) e conduziriam as partidas de acordo com as instruções apresentadas pela pesquisadora na fase de treino. Investigou-se também se o jogo de tabuleiro, aplicado por mães, produziria a leitura e a escrita das palavras ensinadas e de novas palavras formadas a partir da recombinação das sílabas dessas palavras. Embora esse estudo tenha sido uma replicação do trabalho de S. R. Souza e Hübner (2010), algumas pequenas mudanças foram feitas. São elas: (a) ao contrário do estudo de S. R. Souza e Hübner (2010), neste estudo, foram utilizadas como estímulos experimentais palavras cujas sílabas variam sistematicamente de posição e se repetem nas palavras, (b) incluiu-se neste estudo uma fase de seguimento e (c) os aplicadores/jogadores foram as mães e não o pesquisador.

\section{Método}

\section{Participantes}

Participaram três díades (mãe-filho). As crianças tinham 5 anos, desenvolvimento típico e frequentavam a Educação Infantil de uma escola da rede municipal da cidade de Cascavel. As crianças não liam e/ou escreviam. Com exceção da mãe da Díade II, que tinha ensino médio completo, as demais completaram o ensino superior. O trabalho foi aprovado pelo Comitê de Ética com Humanos da Universidade Estadual de Londrina, parecer número 039/2010.

\section{Local}

A coleta de dados foi realizada em uma sala da escola que possuía uma mesa, três cadeiras e um acervo de livros e materiais escolares. As sessões aconteceram no período de aula das crianças.

\section{Estímulos Experimentais}

Foram utilizadas seis palavras de ensino palavras dissílabas simples (correspondência entre grafema e fonema) - divididas em três blocos: BOCA, CABO (Bloco 1), LOBO, BOLO (Bloco 2) e BALA, LATA (Bloco 3). As palavras de generalização, formadas pela recombinação das sílabas das palavras de ensino, foram: LOLO, BOBO, CALO, BOLA, BOTA, LOBA, BATA, TALO. A palavra LOLO refere-se ao chocolate da Nestlé lançado em 1982 que em 1992 passou a chamar-se Milkybar. 


\section{Recursos Materiais}

Foram utilizados DVDs, papel sulfite, canetas e lápis e uma filmadora digital. Os instrumentos utilizados foram a carta de autorização da escola, o Guia de observação dos comportamentos das mães e o tabuleiro temático Abrakedabra: Construindo Palavras (S. R. Souza, 2007).

Guia de Observação dos Comportamentos das Mães. Esse guia, confeccionado nessa pesquisa para guiar o registro da pesquisadora, baseou-se nas regras do jogo e foi dividido em cinco categorias: (a) explicar as regras do jogo à criança, (b) auxiliar a criança, (c) elogiar os comportamentos da criança, (d) repreender comportamentos da criança e (e) chamar a atenção da criança. Nas categorias (a) e (b) foram descritos comportamentos esperados das mães, de acordo com as regras de cada casa do tabuleiro, nas categorias (c) e (d) foram descritos comportamentos que a mãe pudesse emitir como elogios (ex. Muito bem!) ou agressões físicas (ex., bater) ou verbais (ex., Você só pode estar brincando! Faça isso direito!) após os acertos ou erros da criança no decorrer do jogo e na categoria (e) comportamentos da mãe de chamar a atenção do filho(a) para o jogo (ex., Preste atenção!).

Tabuleiro Temático. O jogo tinha início com a entrega de uma das palavras de ensino a criança e outra à pesquisadora. Em seguida, o dado era lançado para determinar quem iniciaria a partida. De acordo com os números correspondentes no dado, o jogador deveria andar com o peão e cumprir o comando da casa na qual parasse. Ganhava o jogo aquele que conseguisse primeiro, construir sua palavra impressa a partir das sílabas e emparelhar a palavra com a figura correspondente. $\mathrm{O}$ tabuleiro temático é composto por 46 casas, descritas em seguida.

Dezesseis casas de famílias silábicas visaram trabalhar as relações entre figura, palavra impressa e/ou palavra falada e conjunto de letras. Essas casas contam com as sílabas de uma dada família silábica, com as letras do alfabeto, em que se excluem as sílabas compostas pelas letras $\mathrm{H}, \mathrm{K}, \mathrm{W}$ e Y (a primeira por não apresentar correspondência entre grafema e fonema e as demais por não fazerem parte do vocabulário brasileiro), e pela família silábica do Q (QUA, QUE, QUI, QUO). Em seis casas de bônus, os jogadores podem pegar uma sílaba do monte, trabalhando as relações entre figura, palavra impressa e/ou palavra falada e conjunto de sílabas.

Nas dez casas de figuras, o jogador deve escolher uma figura, dentre as 45 , correspondente a uma de suas palavras ou sortear uma nova figura e buscar construir a palavra relacionada à figura escolhida, trabalhando a relação entre figura e palavra impressa e/ou falada.

Nas quatro casas de Tarefas, o jogador deveria pegar uma nova palavra do monte e procurar, no decorrer do jogo, completar essa palavra também, ou pegar uma figura do monte de figuras com intuito de construir seu nome com as sílabas ganhas. Quando ocorre a seleção de uma nova palavra ou de uma figura, o jogador deve estabelecer todos os emparelhamentos (relações entre palavra falada, palavra impressa, figura e conjunto de sílabas).

$\mathrm{Na}$ Casa da Biblioteca, o jogador deve sortear uma palavra do monte de palavras e ler. Quando a leitura é correta, ele ganha uma estrela, quando não, o jogo continua normalmente. Nessa casa, o jogador trabalha a relação entre palavra impressa e palavra falada.

O jogo incluía também duas casas da Bruxa que não Sabe Soletrar, três casas da Bruxa que não Sabe Ler e duas casas da Bruxa que não Sabe Escrever, nas quais o jogador deve soletrar, ler ou escrever, respectivamente, de forma correta uma palavra sorteada. Se conseguir, o jogo continua normalmente, caso contrário, perderá uma rodada. É possível trabalhar nessa casa as relações entre palavra impressa e soletração, palavra falada e escrita manuscrita.

Ao cair na Casa de Transporte Escolar, o peão deverá ser levado à Casa da Biblioteca e o jogador terá de ler a palavra do monte, de acordo com o descrito na Casa da Biblioteca, com o mesmo objetivo de trabalhar a leitura.

Da Casa Iniciar partem todos os peões de todos os jogadores no início do jogo e todas as vezes que o jogador passar por ela, ganhará um cartão estrela. Ao juntar três cartões, o jogador poderá escolher uma sílaba do monte. 
Ainda fazem parte do jogo quatro peões de diferentes cores, um dado, três conjuntos de cartões com sílabas impressas das famílias selecionadas para o jogo, um conjunto de cartões com as figuras correspondentes às palavras impressas e cartões com estrelas impressas.

\section{Procedimento}

Etapa 1 (Pré-Teste). Esta etapa foi realizada individualmente com cada criança. Foram testadas as relações entre palavra impressa e palavra falada pela criança (leitura oral), entre palavra falada e conjunto de sílabas (escolha de acordo com o modelo com resposta construída - CRMTS), entre palavra falada e escrita manuscrita (ditado) e entre figura e palavra impressa (emparelhamento entre palavra impressa e figura). Nesta etapa, nenhum feedback foi liberado. As respostas foram seguidas pela apresentação da próxima tentativa.

1. Leitura Oral. As palavras impressas utilizadas no jogo foram apresentadas às crianças e pediu-se a elas que as lessem. Foi the dada a seguinte instrução: "Você sabe o que está escrito aqui? Leia esta palavra para mim".

2. CRMTS. As sílabas de todas as palavras que compõem o ditado manuscrito foram colocadas sobre uma mesa e foi dada a seguinte instrução:

Você sabe o que é uma sílaba? Aqui [apontando para as sílabas] nós temos sílabas formadas por duas letras. Eu vou ditar uma palavra e quero que você monte com estas sílabas as palavras que eu ditar. Caso não saiba, não tem problema. Apenas diga que não sabe e eu ditarei a próxima palavra.

3. Ditado. Nesta etapa, uma folha foi entregue à criança e foi solicitado que ela escrevesse as palavras que a pesquisadora ditasse. As palavras de ensino e de generalização foram ditadas uma de cada vez, pausadamente. As palavras ditadas foram repetidas apenas uma vez, quando necessário.

4. Emparelhamento entre Palavra Impressa e Figura. Todas as palavras de ensino foram colocadas em cima da mesa. Em seguida, a pesquisadora apresentou, de maneira alea- tória, uma a uma, as figuras correspondentes às palavras impressas e fez as seguintes perguntas: "Que figura é esta?", “Onde está escrito (repetir o nome da figura)?"

Etapa 2 (Treino com as Mães). Esta fase foi composta de três sessões com cada mãe, conduzidas individualmente. Na primeira sessão, a pesquisadora explicitou o objetivo e a importância do trabalho a ser realizado. Na segunda sessão, a pesquisadora apresentou o tabuleiro que seria utilizado e jogou por aproximadamente 40 minutos com a mãe. Nessa sessão, a pesquisadora fez o papel da mãe no jogo e a mãe o papel de criança. Na terceira sessão, a mãe e a pesquisadora jogaram, por aproximadamente 40 minutos, e a pesquisadora fez o papel da criança.

Etapa 3 (Intervenção/Jogo). Nesta etapa, foram realizadas as sessões de jogo entre a mãe e a criança. A Díade I foi direcionada para a sala com a presença da pesquisadora. Na primeira sessão, as mães iniciavam o jogo seguindo as instruções dadas anteriormente na fase de treino. Durante as Sessões I, II e III, a pesquisadora auxiliou a mãe durante o jogo. Nas demais sessões, a mãe não foi auxiliada. Utilizou-se nesta pesquisa o delineamento de linha de base múltipla entre díades. Em cada sessão foi realizada apenas uma partida de intervenção/jogo.

Etapa 4 (Sonda). Sessões de sonda, semelhantes em estrutura a sessão de pré-teste, foram realizadas com as crianças a cada três sessões de intervenção/jogo.

Etapa 5 (Seguimento). Depois de transcorridos 25 dias realizou-se, com as crianças, uma nova avaliação, semelhante em estrutura à realizada na etapa de pré-teste. O objetivo dessa sessão foi verificar o desempenho das crianças nas relações ensinadas e testadas depois de um período de tempo. Após a sessão de seguimento, a pesquisadora entregou uma folha às mães e às professoras com questões abertas cujo objetivo era conhecer a opinião delas acerca do trabalho realizado. 


\section{Resultados}

\section{Resultados Apresentados pelas Mães}

No que tange ao comportamento de explicar as regras do jogo à criança, a mãe da Díade I foi a que mais se comportou conforme as orientações da pesquisadora explicando o funcionamento e as regras do jogo ao filho, e a da Díade III foi a que deu menos explicações. A regra da "Casa Iniciar" foi explicada pelo menos uma vez para todas elas. No tabuleiro, há uma "Casa Iniciar" e, na maioria das partidas, os jogadores passam apenas uma vez por essa casa. A mãe da Díade III não explicou a regra da "Casa da Biblioteca" e do "Transporte Escolar" para seu filho, mesmo tendo caído uma vez em cada uma dessas casas. As mães das Díades II e III não caíram na "Casa do Transporte Escolar".
Com relação aos comportamentos de dar auxílio às crianças verifica-se que todas as mães o fizeram em algum momento. Destaca-se o comportamento da mãe da Díade I na "Casa das Figuras" e na "Casa das Tarefas" (39\% e 27\% de auxílio, respectivamente). O auxílio era prestado à criança caso ela necessitasse. Escolher uma figura do monte ou uma palavra não era tarefa complexa para as crianças e, por essa razão, quase não havia necessidade das mães auxiliá-las. Caso o peão de uma das crianças caísse na "Casa da Sílaba", a mãe deveria questionar se ela tinha a sílaba, auxiliá-la a repetir o som das sílabas e a escolher a sílaba apropriada. No entanto, constata-se, que apenas a mãe da Díade I prestou auxílio em todas as vezes. A Tabela 1 apresenta a taxas de elogio, repreensões e chamada da atenção da criança no decorrer do jogo.

Tabela 1

Taxas de Elogios, Repreensões e Chamada da Atenção da Criança no Decorrer do Jogo

\begin{tabular}{lccc}
\hline \multirow{2}{*}{ Comportamentos Avaliados } & \multicolumn{3}{c}{ Taxas (respostas/tempo) } \\
\cline { 2 - 4 } & Mãe I & Mãe II & Mãe III \\
\hline Elogiar os comportamentos & 0,37 & 0,27 & 0,33 \\
Repreender comportamentos & 0,01 & 0,02 & 0,01 \\
Chamar atenção da criança & 0,11 & 0,18 & 0,12 \\
\hline
\end{tabular}

Observa-se que o comportamento de elogiar o desempenho das crianças foi mais frequente que os comportamentos de repreender e ou de chamar sua atenção. Destaca-se aqui que a mãe da Díade I foi a que apresentou maior taxa de elogios e a mãe da Díade II a de chamar atenção da criança para a tarefa que estava sendo executada. As contingências envolvidas no contexto do jogo propiciam um ambiente para comportamentos mais reforçadores que punitivos. Diante disso, os comportamentos das mães no decorrer do jogo possibilitam uma relação mais prazerosa com seus filhos(as) no momento do ensino.

\section{Resultados Apresentados pelas Crianças}

Pré-teste. Nenhum dos participantes escreveu ou leu as palavras apresentadas no Pré-Teste. Eles escreveram apenas sequência de letras, vogais e consoantes e um deles (o P1) escreveu parte de seu nome. Quanto à leitura, o P2 disse nomes de objetos presentes na sala (ex., armário) e o P1 disse o nome de letras (i.e., consoantes e vogais) algumas vezes presentes na palavra apresentada.

No que se refere à construção de palavras, na fase de Pré-Teste, os participantes não as construíram a partir do conjunto de sílabas apresentadas como estímulos de comparação. Eles selecionaram sílabas de maneira aleatória para montar a palavra. O P2 e o P3 geralmente escolhiam apenas uma sílaba quando se pedia que montassem a palavra. O P1 selecionou por duas vezes sílabas correspondente à sílaba das palavras a serem construídas; contudo as escolhas das sílabas parecem ter sido ao acaso. As sílabas estavam dispostas sobre a mesa em uma fileira horizontal e a sua escolha foi realizada median- 
te seleção das duas sílabas das extremidades e depois outras duas das extremidades e assim consecutivamente. Não obstante, o P3 também tenha selecionado por duas vezes as sílabas corretamente, o critério de escolha foi à proximidade das sílabas em relação ao participante.

Quanto à relação entre palavra impressa e figura, o P1 e o P3 conseguiram emparelhar corretamente a figura da bala com a palavra correspondente e o P2 também emparelhou corretamente a figura do bolo. Todavia, como o P1 e o P3 não leram corretamente a palavra BALA e BOLO, respectivamente, no Pré-Teste, sugere-se que os acertos se deram ao acaso.

Intervenção/jogo. Essa fase foi realizada pela díade na presença da pesquisadora. Foram realizadas nove sessões com cada díade. Durante as sessões, o dado foi lançado em média 15 vezes, ou seja, houve quinze jogadas por sessão. Uma jogada se inicia com o lançamento do dado e termina após o jogador completar a tarefa exigida pela casa na qual o peão caiu. O P1 ganhou cinco das nove partidas do jogo, o P2 ganhou três e o P3 ganhou sete das nove partidas realizadas.

Quanto ao desempenho dos participantes na análise de dados levou-se em consideração o seu desempenho nas sessões de Pré-Teste, Sonda e Seguimento. A Figura 1 apresenta a porcentagem de respostas corretas emitidas pelos participantes no que diz respeito às tarefas de leitura, emparelhamento entre figura e palavra escrita e construção das palavras a partir das sílabas (CRMTS). Como nenhuma das crianças escreveu corretamente as palavras de ensino, os dados não foram apresentados na figura.

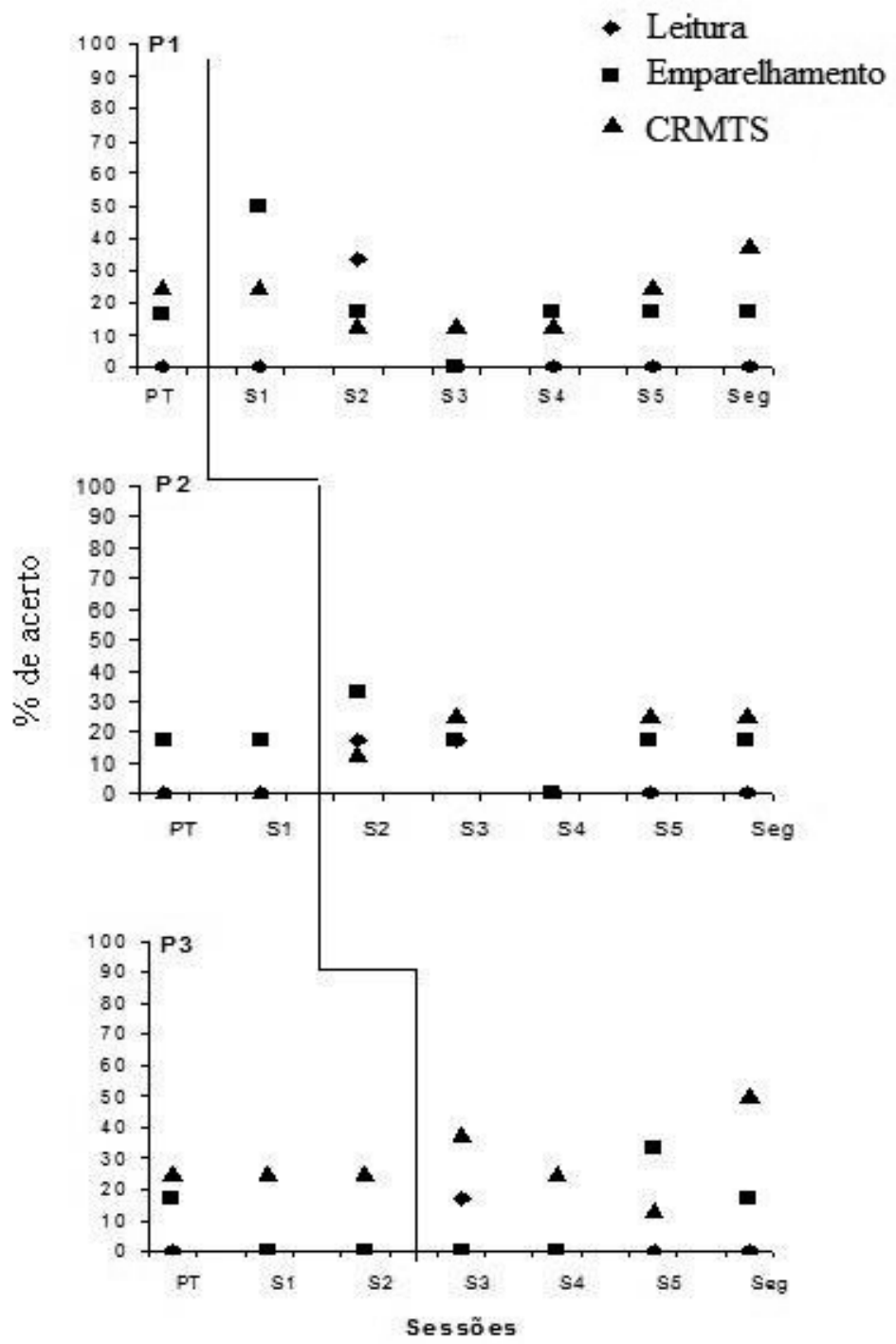

Figura 1. Porcentagem de acerto nas sessões de Pré-teste (PT), Sondas (S) e Seguimento (Seg) com as palavras de ensino nas tarefas de leitura, emparelhamento entre palavra impressa e figura $\mathrm{e}$ CRMTS para o P1, o P2 e o P3. A linha indica 0 início da intervenção jogo. 
Com relação ao comportamento de leitura, quanto às palavras de ensino, o P1 leu corretamente as palavras BOLO e LOBO na sessão de Sonda 2, o P2 leu as palavras BOCA e CABO nas sessões de Sonda 2 e 3, respectivamente, e o P3 leu BOCA na sessão de Sonda 3. Nenhum dos participantes leu as palavras BALA e LATA corretamente. Conquanto tenham sido capazes de ler pelo menos uma palavra ao longo das sessões de sonda os participantes não mantiveram o mesmo desempenho.

No decorrer do jogo, a leitura das palavras era contingente à "Casa da Bruxa que Não Sabe Ler". Sendo assim, o número de vezes que cada criança leu as palavras de ensino variou entre os participantes. Além disso, devido a uma falha de procedimento, na maioria das vezes, as mães pediram às crianças que lessem, durante o jogo, palavras do monte de palavras e não as palavras de ensino. Como as palavras do monte eram muito diferentes das de ensino, em todas as ocasiões nas quais as crianças precisavam ler ou escrever uma palavra, elas necessitaram do auxílio de suas mães. As crianças foram auxiliadas pelas mães, inclusive, quando, em algumas ocasiões, a palavra de ensino foi apresentada. Isso pode ter contribuído para os resultados observados nas sondas de leitura.

Uma análise mais detalhada das casas nas quais o peão das crianças caiu durante o jogo sugere que o número de vezes que as palavras de ensino foram ecoadas não afetou o desempenho das crianças nos testes de leitura (Sondas e Seguimento), pois, embora o P1 tenha sido o participante que emitiu comportamento ecóico com o maior número de palavras na fase de treino (três vezes cada palavra), seu desempenho nas sessões de sonda de leitura foi semelhante ao dos demais participantes. Ainda, o número de vezes nas quais cada um dos participantes jogou com uma dada palavra ou nomeou as sílabas que a compõem também parece não ter interferido nos resultados da leitura. Por exemplo, o P2 e o P3 jogaram uma vez com a palavra BOCA e o P1 duas vezes. Na fase de teste, o P2 e o P3 leram corretamente esta palavra enquanto o P1 não. No caso da nomeação das sílabas, a sílaba BA foi nomeada cinco vezes pelo $\mathrm{P} 1$ e seis vezes pelo
P3, entretanto, a palavra BALA não foi corretamente lida por nenhum deles.

Com relação aos emparelhamentos entre palavra impressa e figura, verifica-se que, com o início da intervenção, houve um aumento no número de emparelhamentos corretos para o P1 e o P2 nas sessões de Sonda 1 e 2, respectivamente, que não se manteve nas sessões seguintes. $\mathrm{Na}$ sessão de Sonda 1, o P1 emparelhou corretamente as palavras BOCA, CABO e BOLO e, na sessão de Sonda 2, a palavra LATA. O P2 emparelhou corretamente as palavras BOLO e LATA na Sessão de Sonda 2 e LATA na sessão de Sonda 3. Na Sonda 4, apenas o P1 apresentou um acerto, referente ao emparelhamento da palavra LOBO. Na Sonda 5, o P1 e o P2 emparelharam corretamente uma palavra (BOLO e BALA, respectivamente) e o $\mathrm{P} 3$ emparelhou corretamente duas palavras (BOLO e LATA). Na sessão de Seguimento, o P1, o P2 e o P3 emparelharam corretamente a palavra BOLO. Ressalta-se que todos os participantes emparelharam corretamente a palavra LATA com a figura correspondente antes mesmo que eles brincassem com esta palavra (Sonda 2 para o P1 e o P2 e Sonda 5 para o P3).

Quanto à tarefa de CRMTS, houve um aumento no número de sílabas corretamente selecionadas das sessões de Sonda para a sessão de Seguimento (Figura 1). Para o P2, embora tenha havido aumento (da sessão de Sonda 3 para a sessão de seguimento), seu desempenho nesta tarefa mostrou-se mais variável. Constatou-se que a maior frequência de acertos relaciona-se à sílaba do início das palavras. $\mathrm{O} \mathrm{P} 1$ selecionou corretamente seis vezes a sílaba $\mathrm{BO}$, sendo quatro vezes no início da palavra, o P2 e o P3 selecionaram corretamente três vezes a sílaba $\mathrm{BO}$ também na posição inicial das palavras.

Com relação às sílabas escritas, apenas o $\mathrm{P} 1$ escreveu corretamente uma sílaba (sílaba "BO") quando a palavra BOCA foi ditada na sessão de Sonda 2. Quando o peão caiu na "Casa da Bruxa que não Sabe Escrever", os participantes foram instruídos a escrever as palavras sorteadas e não as de ensino. Dessa forma, eles não escreveram as palavras de ensino nenhuma vez no decorrer de todas as partidas do jogo, o que provavelmen- 
te impossibilitou o aprendizado da escrita correta das palavras de treino.

Apesar de não ter lido corretamente a palavra BOCA, na fase de teste, o P1 foi o único que escreveu a sílaba BO quando a palavra "boca" foi ditada e também o único a selecionar corretamente a sílaba $\mathrm{BO}$ um número maior de vezes na tarefa de construção da palavra. O P1 jogou quatro vezes com as palavras iniciadas pela sílaba BO (BOCA e BOLO) o P2, três vezes, e o P3, duas vezes. Sugere-se, portanto, que o número de vezes que as crianças jogaram com as palavras BOCA e BOLO foi uma variável importante no que diz respeito à escrita e à tarefa de construção da palavra com as sílabas. Além das palavras de ensino, ao longo do jogo, os participantes também brincaram com outras palavras. O P1 brincou com quatro palavras que possuem sílabas iguais às sílabas das palavras de ensino (CA e LA), o P2 com seis palavras (CA e LO), e o $\mathrm{P} 3$ com oito palavras com sílabas iguais às das palavras de ensino (CA, LA, LO).

Com relação ao desempenho nas palavras de generalização, apenas o P1 leu e escreveu sílabas de pelo menos uma das palavras de generalização. Na Sonda 3, o P1 leu a palavra TALO. Referente à escrita, quando ditada a palavra BOLA, o P1 escreveu corretamente a sílaba BO nas Sondas 2, 3 e 4 e na fase de seguimento.

Os três participantes selecionaram corretamente pelo menos uma sílaba na tarefa de CRMTS quando se ditaram as palavras de generalização. Na fase de Pré-Teste, o P1 selecionou corretamente a sílaba LO quando a palavra LOBA foi ditada. Na Sonda 1, selecionou corretamente quatro sílabas $\mathrm{LO}, \mathrm{BO}, \mathrm{BO}, \mathrm{LO}$ das palavras LOLO, BOLA, BOTA e LOBA. A fase de intervenção que antecedeu a Sonda 1 para essa criança não contemplava palavras com a sílaba $\mathrm{LO}$, entretanto a criança brincou com as palavras GELO e GALO no decorrer das três sessões iniciais de jogo o que parece ter propiciado esse resultado. Na Sonda 2, o P1 selecionou a sílaba LO, correspondente a primeira de LOLO e construiu a palavra CALO corretamente. Nessa fase, além de ter brincado com as palavras de ensino que contêm essas sílabas, o P1 brincou com outras palavras que possuem as sílabas $\mathrm{CA}$ e LO, ora no início ora no final da palavra (FOCA, CAJU, CAPA, GALO, GELO, FACA e SELO). O P1 brincou, ainda, com as palavras VELA, VILA e MALA. Na Sonda 3, o P1 construiu novamente a palavra CALO e a sílaba selecionada foi a sílaba BO correspondente a primeira sílaba da palavra ditada BOLA. Na Sonda 4, obteve quatro acertos referentes às sílabas $\mathrm{LO}, \mathrm{BO}, \mathrm{BO}$ e TA das palavras LOLO, BOBO, BOLA e BATA. Na Sonda 5 , construiu corretamente a palavra BOTA e, na fase de seguimento, ele construiu pela terceira vez a palavra CALO e selecionou corretamente as sílabas LO (LOLO), BO (BOLO), BO (BOTA), LO (LOBA) e TA (BATA).

O P2 selecionou corretamente a sílaba BO da palavra BOLA na Sonda 2 e BO e LO das palavras BOTA e LOBA na Sonda 4. O P3, antes da fase de intervenção, selecionava as sílabas de ponta-cabeça e de forma aleatória. Entretanto, após a intervenção, ele selecionou corretamente a sílaba LO (LOBA) na Sonda 3, quatro sílabas na Sonda 4 (LO, BO, LO e TA) das palavras LOLO, BOLA, LOBA e BATA e duas sílabas na Sonda 5 (LO e BO) das palavras CALO e BOLA. $\mathrm{Na}$ fase de Seguimento selecionou corretamente as sílabas BO e LO quando as palavras BOLA e TALO foram ditadas.

\section{Discussão}

As mães aprenderam as regras do jogo, visto que elas foram capazes de conduzir as partidas de acordo com as instruções apresentadas pela pesquisadora na fase de treino. A mãe da Díade I apresentou, em 100\% das rodadas em que o peão caiu nas "Casas das Sílabas", os comportamentos de explicar as regras do jogo e de dar auxílio. As regras dessa casa permitiam que a criança emitisse o comportamento ecóico e a discriminação das sílabas que compunham as palavras da partida. O P1 selecionou o maior número de sílabas corretas das palavras de generalização e escreveu a sílaba BO quatro vezes e a palavra TALO uma vez. A mãe da Díade I também apresentou a maior taxa de elogios. Como todo comportamento operante, os comportamentos de ler e escrever precisam ser reforçados para serem aprendidos e mantidos (de Rose, 2005). 
Comparando-se os resultados referentes às taxas de repreensões dos comportamentos das crianças neste estudo com outros estudos que avaliavam essa categoria durante a realização da tarefa de casa (Sampaio et al., 2004; Scarpelli et al., 2006), as taxas de repreensões constatadas no momento da realização da tarefa de casa foram superiores às taxas verificadas no presente estudo no decorrer da fase de intervenção/jogo. O contexto propiciado pelo jogo reduz a probabilidade de broncas e repreensões pela mãe, o que facilita o engajamento da criança e o envolvimento dos pais em atividades relacionadas ao contexto escolar. O envolvimento dos pais no processo de ensino dos conteúdos escolares é de suma importância para que a criança valorize o comportamento de estudar. Quando este envolvimento acontece por meio de um jogo, a relação pode tornar-se prazerosa para a criança e seus pais, pois o jogo propicia contingências mais reforçadoras (Brenelli, 1996).

Finalmente, no questionário aplicado ao final da fase de seguimento, cuja finalidade era avaliar o jogo como recurso pedagógico pelas mães, constatou-se que todas elas apontaram aspectos positivos do uso do jogo. A mãe da Díade I escreveu ". . . avalio excelente recurso, pois além de um momento individualizado e exclusivo junto à mãe, reforçando os vínculos afetivos, pode vivenciar situações ricas e desafiadoras proporcionadas pelo jogo como recurso pedagógico"; ". . . além de ser uma atividade prazerosa e dinâmica... foi um momento nosso [sic]". A mãe da Díade II escreveu: “. . . é uma forma interessante de ensinar pois prende a atenção da criança [sic]" e a mãe da Díade III acrescentou: “. . . notei que ele ficou motivado [sic]". Os relatos das mães reafirmam a necessidade de desenvolver tecnologias para o ensino de leitura e escrita que permitam o envolvimento dos pais.

Quanto ao desempenho das crianças durante o jogo, os resultados dos testes mostram que, com o início da intervenção/jogo, houve um aumento na porcentagem de acerto principalmente no que diz respeito às tarefas de emparelhamento entre palavra impressa e figura e escolha de acordo com o modelo com resposta construída.
Quanto ao desempenho em leitura e a escrita, não se verificou mudanças muito expressivas. Entretanto, é importante considerar que mesmo as pequenas mudanças observadas foram obtidas com nove partidas de jogo, após tempo médio de ensino de quatro horas e doze minutos (quatro horas e dezesseis minutos para o $\mathrm{P} 1$, quatro horas e vinte e oito minutos para o $\mathrm{P} 2$ e três horas e cinquenta e um minuto para o P3).

Ainda em relação aos resultados, constata-se que as palavras de ensino BALA e LATA não foram lidas por nenhum dos participantes nas sessões de Sonda e Seguimento. Na fase de ensino, essas palavras foram lidas pelo menos uma vez por cada participante, entretanto, não foram soletradas durante o jogo como aconteceu com as demais palavras. Isso sugere que a soletração oral pode ser importante para a aquisição de leitura das palavras. Também é necessário destacar que as sílabas BA e TA dessas palavras não foram apresentadas nas demais palavras de ensino. De acordo com Hübner-D’Oliveira e Matos (1993), para que haja melhor controle discriminativo das unidades mínimas, é necessário que tanto as sílabas ocupem posições diferentes nas palavras de ensino quanto seja realizada uma recombinação de letras. Serejo, Hanna, de Souza e de Rose (2007) também apontam como variáveis críticas para a emergência do controle por unidades menores e leitura recombinativa, o número de conjuntos de palavras ensinadas. A possibilidade de brincar com várias palavras, que possuem as sílabas em posições diferentes, pode ser considerada uma variável importante para explicar esse resultado. Esses dados corroboram os de Serejo et al. (2007) que apontam como variáveis críticas a forma como as unidades menores que a palavra são recombinadas sistematicamente ao longo do procedimento.

Outro aspecto a ser considerado é o de que as crianças foram expostas a um maior número de sessões com palavras que iniciavam com a sílaba BO (BOCA e BOLO). A sílaba BO aparecia também nas palavras $\mathrm{CABO}$ e $\mathrm{LOBO}$, permitindo que as crianças brincassem com palavras nas quais essa sílaba aparece também no final. De acordo com de Rose (2005), a aquisi- 
ção de controle por dimensões como posição e som requer que a criança seja exposta a atividades que envolvam a discriminação de posição e de sons com feedback para as respostas. Além de atividades mais formais, jogos e brincadeiras que envolvem esse tipo de discriminação podem constituir oportunidades de ensino. As regras do jogo usado neste estudo permitiam ao aplicador, neste caso, as mães, ensinar a discriminação do som das sílabas.

Nos testes de ditado, apenas uma das crianças escreveu uma sílaba das palavras de ensino. A relação entre a palavra falada e a escrita manuscrita foi trabalhada no jogo somente quando as crianças caíam na "Casa da Bruxa que não Sabe Escrever". Devido a uma falha técnica, as mães foram orientadas a solicitar que seus filhos escrevessem uma palavra sorteada do monte e não a palavra de ensino, diferentemente da instrução dada no estudo de S. R. Souza e Hübner (2010). Outra diferença com relação ao presente estudo refere-se à aplicação de um procedimento adicional que, de acordo com as autoras, pode ter colocado as crianças sob controle das letras que compõem as palavras e melhorado seu desempenho nas sessões de ditado. Nesse procedimento, as crianças eram solicitadas a ler as palavras para a pesquisadora e em seguida copiá-las em papel previamente fornecido. Caso houvesse necessidade, a pesquisadora poderia ajudar. Posteriormente, as palavras eram retiradas e as crianças deveriam escrevê-las sem a presença da palavra impressa como modelo. Por fim, as palavras eram novamente apresentadas às crianças para comparação com a palavra que escreveram e, caso necessário, correções eram feitas. A não realização do procedimento adicional e a falha na instrução das mães deste estudo podem ter contribuído para que as crianças não escrevessem as palavras de ensino diferentemente do que aconteceu no estudo de S. R. Souza e Hübner (2010).

Com relação ao desempenho no teste de leitura com as palavras de generalização, apenas uma criança leu uma palavra (TALO). É importante destacar que as sessões de jogo tiveram duração aproximada de 35 minutos e no total não excederam a quatro horas e meia. Segundo Hübner-D’Oliveira e Matos (1993), uma maior exposição ao treinamento é uma variável a ser considerada quando se trata de emergência de leitura recombinativa.

Em vista dos resultados obtidos, verifica-se a necessidade de novas investigações que orientem a mãe mais apropriadamente quanto ao cumprimento das regras do jogo referente à "Casa da Bruxa que Não Sabe Escrever e Ler". Além disso, para que se possa comparar os resultados de estudos dessa natureza com os de S. R. Souza e Hübner (2010), o mesmo procedimento adicional empregado naquela pesquisa deverá ser usado. Estudos posteriores poderiam, ainda, disponibilizar às mães um manual de instruções que explicasse como utilizar o jogo.

Além dos aspectos citados acima, é possível que as crianças tenham um melhor desempenho se as mães tiverem um maior número de sessões na fase de treino e as crianças, um maior número de sessões de jogo. Segundo resultados obtidos por S. R. Souza e Ximenes (2011), um número maior de sessões com o jogo (por volta de oito a 12 sessões) é necessário para que se observe leitura e escrita recombinativa.

Outra variável que poderia ser manipulada refere-se à presença da pesquisadora na sala, no decorrer da fase de intervenção/jogo. Sugere-se que novos estudos sejam realizados sem a presença da pesquisadora. De acordo com Scarpelli et al. (2006), a presença da pesquisadora no momento da realização da tarefa escolar pode ser uma variável de controle para a diminuição das taxas de repreensões. Finalmente, sugere-se que os próximos estudos na área de equivalência de estímulos e aprendizagem de leitura e escrita utilizando jogos sejam realizados com um número maior de díades. Participaram deste estudo apenas três díades. Um maior número de díades contribuiria para a generalização dos resultados.

\section{Referências}

Bomtempo, E. (1999). Brinquedo e educação: Na escola e no lar. Psicologia Escolar e Educacional, 3(1), 61-69.

Brenelli, R. P. (1996). Ojogo como espaço para pensar: A construção de noções lógicas e aritméticas. Campinas, SP: Papirus. 
De Rose, J. C. (2005). Análise comportamental da aprendizagem de leitura e escrita. Revista Brasileira de Análise do Comportamento, 1(1), 29-50.

De Rose, J. C. C., de Souza, D. G., \& Hanna, E. S. (1996). Teaching reading and spelling: Exclusion and stimulus equivalence. Journal of Applied Behavior Analysis, 29, 451-469. doi:10.1901/jaba.1996.29-451

Dube, W. V., McDonald, S. J., McIlvane, W. J., \& Mackay, H. A. (1991). Constructed-response matching to sample and spelling instruction. Journal of Applied Behavior Analysis, 24(2), 305-317. doi:10.1901/jaba.1991.24-305

Fehrmann, P. G., Keith, T. Z., \& Reimers, T. M. (1987). Home influence on school learning: Direct and indirect effects of parental involvement on high school grades. The Journal of Educational Research, 80(6), 330-337. doi:10.2307/27540261

Ferreira, A. C. M., Gris, G., Oliveira, G. T., Alves, H. W., Haydu, V. B., Costa, C. E., \& Souza, S. S. (2012). O uso de jogos como instrumentos para o ensino de principios/conceitos de análise experimental do comportamento. In V. B. Haydu \& S. R. Souza (Eds.), Psicologia Comportamental Aplicada: Avaliação e intervenção nas áreas da saúde, da clínica, da educação e do esporte (Vol. 2, pp. 269-293) Londrina, PR: Editora da Universidade Estadual de Londrina.

Hanna, E. S., Karino, C. A., Araújo, V. T., \& de Souza, D. G. (2010). Leitura recombinativa de pseudopalavras impressas em pseudoalfabeto: Similaridade entre palavras e extensão da unidade ensinada. Psicologia USP, 21(2), 275-311. doi:10.1590/S0103-65642010000200005

Hübner, M. M. (1999). Contingências e regras familiares que minimizam problemas de estudo: A família pró-saber. In R. R. Kerbauy \& R. C. Wielenska (Eds.), Sobre comportamento e cognição: Psicologia Comportamental e Cognitiva - Da reflexão teórica à diversidade na aplicação (Vol. 4, pp. 251-256). Santo André, SP: Arbytes.

Hübner-D’Oliveira, M. M., \& Matos, M. A. (1993). Controle discriminativo na aquisição de leitura: Efeito da repetição e variação na posição das sílabas e letras. Temas em Psicologia, 1(2), 99 108.

Mackay, H. A., \& Sidman, M. (1984). Teaching new behavior via equivalence relations. In $\mathrm{P}$. H. Brooks, R. Sperber, \& C. MacCauley (Eds.),
Learning and cognition in mentally retarded (pp. 493-513). Hillsdale, NJ: Erlbaum.

Marturano, E. M. (1999). Recursos no ambiente familiar e dificuldades de aprendizagem na escola. Psicologia Teoria e Pesquisa, 15(2), 135-142. doi:10.1590/S0102-37721999000200006

Matos, M. A., Hübner, M. M., Serra, V. R. B. P., \& Avanzi, A. L. (2002). Redes de relações condicionais e leitura recombinativa: Pesquisando o ensinar a ler. Arquivos Brasileiros de Psicologia, 54, 284-302.

Sampaio, A. C., Souza, S. R., \& Costa, C. E. (2004). Treinamento de mães no auxílio à execução da tarefa de casa. In M. Z. Brandão, F. C. S. Conte, F. S. Brandão, Y. K. Ingberman, V. L. M. Silva, \& S. M. Oliani (Eds.), Sobre comportamento e cognição: Contribuições para a construção da teoria do comportamento (Vol. 14, pp. 295309). Santo André, SP: Arbytes.

Scarpelli, P. B., Costa, C. E., \& Souza, S. R. (2006). Treino de mães na interação com os filhos durante a realização da tarefa escolar. Estudos de Psicologia, 23, 55-65. doi:10.1590/S0103$-166 \times 2006000100007$

Serejo, P., Hanna, E. S., de Souza, D. G., \& de Rose, J. C. C. (2007). Leitura e repertório recombinativo: Efeito da quantidade de treino e da composição dos estímulos. Revista Brasileira de Análise do Comportamento 3, 191-215.

Soares, M. R. Z., Souza, S. R., \& Marinho, M. L. (2004). Envolvimento dos pais: Incentivo à habilidade de estudo em crianças. Estudos de Psicologia (Campinas), 21(3), 253-260. doi:10.1590/ S0103-166X2004000300009

De Souza, D. G., \& de Rose, J. C. (2006). Desenvolvendo programas individualizados para o ensino de leitura. Acta Comportamentalia, 14(1), 7798.

Souza, J. A. N., \& Assis, G. J. A (2013). Instalando pré-requisitos de leitura para dois alunos com deficiência intelectual. Psicologia: Teoria $e$ Prática, 15(2), 130-143.

Souza, S. R. (2000). Aquisição de habilidades de leitura e escrita: Um percurso do laboratório a clínica-escola (Tese de doutorado em Psicologia Clínica, Universidade de São Paulo, SP, Brasil).

Souza, S. R. (2007). AbraKedabra: Construindo palavras [Jogo de tabuleiro]. Londrina, PR. 
Souza, S. R., Goyos, A. C. N., Silvares, E. F. M., \& Saunders, R. R. (2007). Emergence of printing and spelling skills from constructed-response matching-to-sample instruction (CRMTS). European Journal of Behavior Analysis, 8, 49-64.

Souza, S. R., \& Hübner, M. M. C. (2010). O ensino de leitura e escrita por meio do procedimento de construção de anagramas: Elaboração e avaliação de um tabuleiro. Acta Comportamentalia, $18,215-242$.

Souza, S. R., \& Ximenes, V. (2011). Ensino de leitura recombinativa: Efeito do número de sessões com uso de um jogo de tabuleiro. Manuscrito não publicado.

Stromer, R., Mackay, H. A., \& Stoddard, L. T. (1992). Classroom applications of stimulus equivalence technology. Journal of Behavioral Education, 23, 225-256. doi:10.1007/BF00948817
Skinner, B. F. (1972). Tecnologia do ensino (R. Azzi, Trad.). São Paulo, SP: Editora Pedagógica e Universitária. (Original publicado em 1968)

Xander, P. (2013). "Dimdim: Negociando \& brincando" no ensino de habilidades monetárias a pré-escolares (Dissertação de mestrado em Análise do Comportamento, Universidade Estadual de Londrina, PR, Brasil). Recuperado em http://www.uel.br/pos/pgac/wp-content/uploads/2014/03/Dimdim-negociando-brincando_no-ensino-de-habilidades-monet $\% \mathrm{C} 3 \% \mathrm{~A} 1$ rias-a-pr\%C3\%A9-escolares.pdf

Recebido: 09/07/2013

$1^{a}$ revisão: 09/01/2014

$2^{a}$ revisão: $1 \% 4 / 2014$ Aceite final: 04/04/2014 